\title{
Desempenho de cultivar de soja de crescimento determinado em diferentes arranjos espaciais
}

Paula Daiane de Sena Martins ${ }^{1}$, Eduardo Lima do Carmo ${ }^{1}$, Alessandro Guerra da Silva ${ }^{1}$, Sérgio de Oliveira Procópio $^{2}$, Gustavo André Simon ${ }^{1}$, Christiano Lima Lobo de Andrade ${ }^{3}$

${ }^{1}$ Universidade de Rio Verde - UniRV, GO. ${ }^{2}$ Embrapa Tabuleiros Costeiros. ${ }^{3}$ Instituto Federal Goiano - IF Goiano, GO. Email: christiano.instrutoria@gmail.com

\section{Resumo}

A adoção de diferentes arranjos de plantas na cultura da soja pode promover alterações morfológicas nas plantas, o que pode influenciar a produtividade de grãos. Neste contexto, o arranjo espacial aliado ao uso de cultivares de crescimento determinado e de maior ciclo pode ser uma alternativa para o manejo da soja em condições edafoclimáticas adversas. Dessa forma o objetivo deste trabalho foi avaliar o desempenho agronômico e os componentes de produtividade da cultivar BRS Valiosa RR ${ }^{\circledR}$, de crescimento determinado, em diferentes espaçamentos entrelinhas e populações de plantas. O ensaio foi instalado em Rio Verde/GO na safra 2012/13, no delineamento experimental de blocos casualizados em arranjo fatorial $4 \times 4$, com quatro repetições. Foram avaliados quatro espaçamentos entrelinhas (20; 40; $20 / 40$ e $20 / 60 \mathrm{~cm}$ de entrelinhas) associados a quatro populações de plantas (200.000; 300.000; 400.000 e 500.000 plantas ha ${ }^{-1}$ ). A cultivar BRS Valiosa $\mathrm{RR}^{\circledast}$ apresentou potencial para redução da população de plantas sem ocasionar reduções em produtividade, independente do espaçamento entrelinhas.

Palavras-chave: componentes de produtividade; espaçamento entrelinhas; Glycine max; população de plantas; produtividade de grãos.

\section{Performance of determined growth soybean cultivar under different spatial arrangements}

\begin{abstract}
The adoption of different plant arrangements in the soybean crop can promote morphological changes in the plants, which may influence the grain yield. In this context, the spatial arrangement allied to a determined growth and higher cycle variety may be an alternative for the management of the soybean crop under adverse edaphic-climatic conditions. In this way, the objective of this work was to evaluate the agronomic performance and the productive components of the BRS Valiosa RR soybean cultivar, with determined growth in different plant populations and between rows. The trial was installed in Rio Verde/GO at 2012/13 agricultural year. A randomized complete block design was used in a factorial arrangement $4 \times 4$ with four replications. It was evaluated four spacing between rows (20; $40 ; 20 / 40$ and $20 / 60 \mathrm{~cm})$ associated with four plant populations $\left(200,000,300,000,400,000\right.$ and 500,000 ha ${ }^{-1}$ plants). The BRS Valiosa $\mathrm{RR}^{\circledR}$ cultivar showed potential to reduce the plant population without causing reductions in grain yield, regardless of the spacing between rows.
\end{abstract}

Keywords: yield components; spacing between rows; Glycine max; plant population; grain yield.

\section{Introdução}

Atualmente o sistema de produção agrícola nos cerrados é caracterizado pelo sistema de sucessão de culturas em plantio direto, principalmente com uso da soja no verão e do milho e sorgo em sucessão (VILELA et al., 2011). Em função das condições edafoclimáticas e da tecnologia empregada nas propriedades agrícolas, este modelo trouxe grande sucesso ao agronegócio. Entretanto, ao longo dos anos, os 
cultivos sucessivos e o posicionamento de cultivares tem limitado a obtenção de produtividade das culturas ou mesmo reduzindo a lucratividade do produtor rural (CRUZ et al., 2016).

Neste contexto, é essencial que a recomendação de variedades de soja seja realizada com base em sua adaptabilidade as variações edafoclimáticas e na estabilidade de produção (KOMATSU et al., 2010; CARMO et al., 2018). Cultivares de hábito de crescimento determinado e de período juvenil longo, com grupo de maturação maior que oito, tornam-se uma opção interessante para o cultivo em solos de baixa fertilidade e/ou implantação em semeaduras tardias (BALBINOT et al., 2015). Por outro lado, cultivares de menor ciclo, ou seja, de grupo de maturação inferior a oito, quando semeadas tardiamente ou em condições de baixa fertilidade, tem florescimento precoce e consequentemente sujeitas a redução no porte, no acúmulo de massa seca e consequentemente na produtividade de grãos (PERIN et al., 2012; BALBINOT et al., 2015). Nessas condições, tornase essencial o uso de cultivares de maior ciclo, com o intuído de se retardar o florescimento das plantas para possibilitar o maior crescimento vegetativo, e consequentemente, maior produtividade (SEDIYAMA et al., 2009; PERIN et al., 2012).

Associado a isto, uma das tecnologias que despertou 0 interesse dos produtores para aumento da produtividade dos grãos da soja foi a adoção de arranjos de plantas diferentes daqueles adotados na maioria dos cultivos de soja (CRUZ et al., 2016; CARMO et al., 2018). As modificações feitas no arranjo, principalmente alterando o cultivo de soja no espaçamento entrelinhas de 40 a $50 \mathrm{~cm}$, proporcionam alterações morfológicas nas cultivares e influenciaram a captação de luz pelo dossel das plantas (MAUAD et al., 2010; SILVA et al., 2010). Adicionalmente, em regiões com maior temperatura, o aumento da população de plantas contribui no aumento do porte das plantas, favorecendo o aumento dos componentes da produtividade da soja (ROCHA et al., 2012).

Devido à plasticidade fenotípica das cultivares de soja, os componentes de produtividade podem variar conforme o arranjo de plantas (BIANCHI et al., 2010; MADALOSSO et al., 2010; MAUAD et al., 2010; SILVA et al., 2010). Mesmo com a capacidade de adaptar as condições de manejo, o uso de menores espaçamentos promove o fechamento mais rápido das entrelinhas, aumentando a competição entre as plantas pelos recursos ambientais, principalmente por luz (MADALOSSO et al., 2010; MODOLO et al., 2016). Dessa forma, a adequação do arranjo de plantas de soja proporcionará melhorias no aproveitamento de água e nutrientes e consequentemente acréscimos na produtividade de grãos de soja (BOARD; KAHLON, 2013).

Portanto, a utilização de diferentes arranjos espaciais tem se destacado como opção de manejo para o aumento da produtividade de grãos (BRACHTVOGEL et al., 2009). No entanto, trabalhos relacionados ao arranjo espacial em cultivares de soja de hábito de crescimento determinado são limitados (PROCÓPIO et al., 2014; BALBINOT JÚNIOR et al., 2015), principalmente em condições do cerrado brasileiro, em que os solos são caracterizados por apresentarem menor fertilidade (SANTOS et al., 2013).

Dessa forma, a hipótese deste estudo é de que os espaçamentos de plantio e a população de plantas, de forma independente, possam influenciar nos componentes de produtividade da cultura da soja. Entretanto o ajuste ideal do espaçamento aliado a população de plantas podem proporcionar incrementos significativos nos componentes de produtividade.

Sendo assim, o objetivo deste trabalho foi avaliar o desempenho agronômico e os componentes de produtividade do cultivar de soja de crescimento determinado BRS Valiosa RR ${ }^{\circ}$ em diferentes arranjos espaciais de plantas nas condições do cerrado.

\section{Material e métodos}

O ensaio foi conduzido a campo no município de Rio Verde/GO, na região Sudoeste

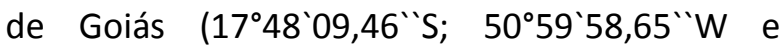
altitude de $750 \mathrm{~m}$ ) na safra agrícola 2012/13, tendo como cultura antecessora o milho, cultivado no sistema plantio direto. O clima na localidade é do tipo Aw, sendo caracterizado como tropical com estação seca, com chuvas mais intensas no verão em relação ao inverno (Köppen). Os dados climáticos durante a condução do ensaio estão apresentados na Figura 1. 
Figura 1. Valores médios de precipitação $(\mathrm{mm})$, temperatura máxima, mínima e média $\left({ }^{\circ} \mathrm{C}\right)$, umidade relativa média (\%) e evapotranspiração real (ETc) durante a condução do ensaio. Rio Verde/GO, safra 2012/13.

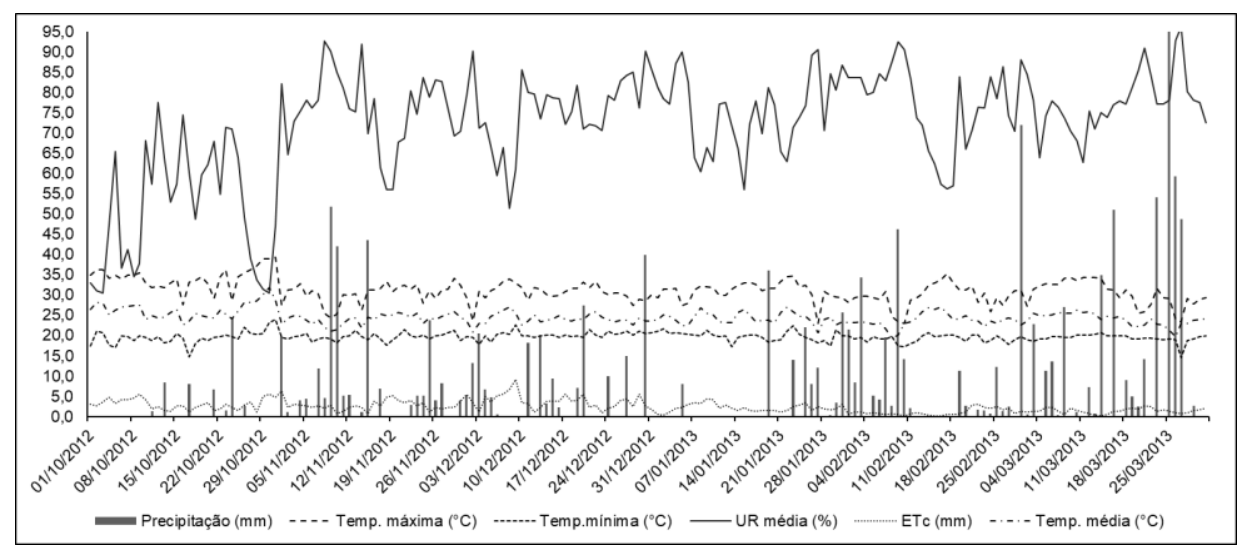

O solo da área experimental foi classificado como Latossolo Vermelho distroférrico (SANTOS et al., 2013). Os resultados da análise físicoquímica da amostra o solo coletado na camada de 0 a $20 \mathrm{~cm}$ de profundidade, apresentou as seguintes características: $\mathrm{pH}$ em $\mathrm{CaCl}_{2}: 4,4 ; \mathrm{Ca}$ : 1,6; Mg: 0,8; K: 0,2; Al: 0,5; H+Al: 4,8; CTC: 7,4 e SB: 2,6 , em cmol $\mathrm{cm}^{-3} ; \mathrm{P}: 1,8 \mathrm{mg} \mathrm{dm}^{-3}$; saturação de bases e de alumínio: 35 e 16\%; argila, silte e areia: 500, 110 e 390, em g kg-1, respectivamente.

$O$ delineamento utilizado foi o de blocos ao acaso com quatro repetições no arranjo fatorial $4 \times 4$, considerando quatro espaçamentos entrelinhas $(0,2 \mathrm{~m}$ [reduzido]; $0,4 \mathrm{~m}$ [convencional]; $0,2 / 0,4 \mathrm{~m}$ [fileiras duplas reduzidas]; e 0,2/0,6 $\mathrm{m}$ [fileiras duplas]) associados a quatro populações de plantas (200.000 plantas $\mathrm{ha}^{-1}: 66 \%$ da população recomendada; 300.000 plantas ha $^{-1}$ : população recomendada; 400.000 plantas $\mathrm{ha}^{-1}$ : acréscimo de $33 \%$ da população recomendada; e 500.000 plantas ha ${ }^{-1}$ : acréscimo de $66 \%$ acima da população recomendada).

As unidades experimentais continham seis linhas de 5,0 $\mathrm{m}$ de comprimento por 3,2 $\mathrm{m}$ de largura, sendo a área útil obtida desconsiderando $0,4 \mathrm{~m}$ de cada lado e 1,0 $\mathrm{m}$ de cada extremidade, apresentando, portanto, 7,2 $\mathrm{m}^{2}$. Desta forma, a área útil das parcelas continha seis linhas para os arranjos com espaçamento entrelinhas de 40 e de $20 / 60 \mathrm{~cm}$, oito linhas para o de $20 / 40 \mathrm{~cm}$ e doze para o arranjo com espaçamento entrelinhas de $20 \mathrm{~cm}$.

A cultivar empregada foi a BRS Valiosa $R^{\circ}$, caracterizada por apresentar hábito de crescimento determinado, período juvenil longo com grupo de maturação 8.1 para a microrregião de execução do ensaio. Além destas características essa cultivar é recomendada para cultivo em solos de menor fertilidade (ZITO et al., 2012).

A dessecação das plantas daninhas foi realizada mecanicamente uma semana antes da semeadura com uso de $1.920 \mathrm{~g}$ e.a $\mathrm{ha}^{-1}$ de glyphosate e $536 \mathrm{~g}$ i.a. ha ${ }^{-1}$ de 2,4-D com volume de calda de $150 \mathrm{~L} \mathrm{ha}^{-1}$. No dia da semeadura, as sementes foram tratadas com [piraclostrobina + tiofanato metílico + fipronil] $\left(0,20 \mathrm{~L} 100 \mathrm{~kg}^{-1} \mathrm{de}\right.$ sementes), Mo (0,028 L $100 \mathrm{~kg}^{-1}$ de sementes) e inoculante líquido (Bradyrhizobium elkanii; concentração de $5 \times 10^{9}$ ) na proporção de $0,15 \mathrm{~L}$ $100 \mathrm{~kg}^{-1}$ de sementes. A semeadura foi realizada em 23 de novembro de forma mecanizada, sendo empregado o equivalente a $90 \mathrm{~kg} \mathrm{ha}^{-1}$ de $\mathrm{K}_{2} \mathrm{O}$ e $\mathrm{P}_{2} \mathrm{O}_{5}$ no sulco de semeadura. Aos 25 dias após a emergência (DAE), foi realizada a aplicação a lanço, de forma mecanizada, de $200 \mathrm{~kg} \mathrm{ha}^{-1}$ de $\mathrm{KCl}$.

Aos 10 DAE foi realizado o desbaste das plântulas para se ter as densidades de semeaduras desejadas nos respectivos tratamentos. Os tratos culturais foram realizados de acordo com os recomendados para a cultura, procedendo ao controle de pragas e doenças a fim de não haver interferência desses fatores nas características analisadas (BUENO et al., 2014). Já as plantas daninhas foram manejadas com duas capinas manuais, aos 10 e aos 20 DAE, para evitar a interferência no desenvolvimento das plantas de soja.

Quando a cultura atingiu o estádio reprodutivo $R_{6}$ (completo enchimento de grãos; escala proposta por RITCHIE et al., 1993) foi realizada a avaliação de massa seca da parte 
aérea. Nesta, foram coletadas dez plantas por parcela, sendo separadas na altura do colo. $O$ material vegetal foi acondicionado em sacos de papel, levados à estufa com circulação forçada a $65^{\circ} \mathrm{C}$ por $72 \mathrm{~h}$ até atingir massa constante.

A colheita foi realizada aos 118 DAE (21 de março de 2013) sendo avaliada, na área útil das parcelas, a produtividade (colheita das plantas com debulha das vagens e pesagem dos grãos com correção da umidade para 13\%) e massa de mil grãos (pesagem de mil grãos a partir da amostra de produtividade, com correção da umidade para 13\%); altura de plantas e de inserção da primeira vagem (medição do colo ao último trifólio completamente expandido e até a inserção da primeira vagem, respectivamente); número total de vagens na haste principal com três, dois e um grão; número de hastes secundárias e de vagens nestas hastes (contagem em dez plantas contínuas).

Os dados foram submetidos a análise de variância. Quando constatada significância para determinada variável, empregou-se o teste de Tukey $(p<0,05)$ e análise de regressão para comparação das médias dos espaçamentos entrelinhas e populações de plantas, respectivamente. Previamente a realização da ANOVA, foram realizados os testes de normalidade e homogeneidade das variâncias para verificar as pressuposições para realização das análises estatísticas. Quando necessário, os dados foram transformados para raiz quadrada de $(x+1)$.

\section{Resultados e discussão}

Tabela 1. Resultados da análise de variância das variáveis produtividade (PROD) e massa de mil grãos (M1000G), massa seca da parte aérea (MS), alturas de plantas (ALT) e de inserção da primeira vagem (AIV), número total de vagens na haste principal (NVHP) com três (NVHP3G), dois (NVHP2G) e um grão (NVHP1G), número de hastes secundárias (NHS) e de vagens nessa haste do cultivar BRS Valiosa RR em função do espaçamento entrelinhas e da população de plantas, Rio Verde/GO, safra 2012/13.

\begin{tabular}{|c|c|c|c|c|c|c|c|}
\hline F.V. & $\overline{\mathrm{GL}}$ & PROD & M1000G & & AS & $\overline{\mathrm{ALT}}$ & AIV \\
\hline Espaçamento (E) & 3 & $197237,27^{\text {ns }}$ & $192,75^{\mathrm{ns}}$ & 634 & $08,43^{\text {ns }}$ & $112,57^{\text {ns }}$ & $29,76^{\text {ns }}$ \\
\hline População (P) & 3 & $227839,01^{\text {ns }}$ & $992,97^{\mathrm{ns}}$ & 1125 & $73,37^{* *}$ & $417,67^{*}$ & $25,68^{\mathrm{ns}}$ \\
\hline$E \times P$ & 9 & $164984,15^{\text {ns }}$ & $213,60^{\text {ns }}$ & & $33,54^{\mathrm{ns}}$ & $92,73^{\mathrm{ns}}$ & $10,08^{*}$ \\
\hline C.V. (\%) & & 16,4 & 10,0 & & 8,5 & 12,7 & 14,6 \\
\hline F.V. & $\mathrm{GL}$ & NVHP & NVHP3G & NVHP2G & NVHP1G & NHS & NVHS \\
\hline Espaçamento (E) & 3 & $36,77^{*}$ & $5,81^{\text {ns }}$ & $5,18^{\text {ns }}$ & $1,09^{\text {ns }}$ & $0,04^{\mathrm{ns}}$ & $2,44^{\text {ns }}$ \\
\hline População (P) & 3 & $157,68^{* *}$ & $30,06 * *$ & $34,51 * *$ & $0,76^{\mathrm{ns}}$ & $8,80 * *$ & $686,33^{* *}$ \\
\hline$E \times P$ & 9 & $14,20^{*}$ & $3,81^{\mathrm{ns}}$ & $3,31^{\mathrm{ns}}$ & $0,83^{\mathrm{ns}}$ & $0,24^{\mathrm{ns}}$ & $8,79^{\mathrm{ns}}$ \\
\hline C.V. (\%) & & 13,5 & 22,6 & 13,0 & 32,1 & 24,1 & 28,5 \\
\hline
\end{tabular}


${ }^{* *},{ }^{*}{ }^{\text {ns }}$ : significativo a 1 e $5 \%$ de probabilidade de erro e não significativo, respectivamente, pelo teste $\mathrm{F}$. FV: Fontes de variação; GL: Graus de liberdade; CV: Coeficiente de variação.

Adicionalmente, no segundo decêndio de fevereiro, quando as plantas estavam na fase de enchimento de grãos, houve a ocorrência de um período com menor ocorrência de chuvas (Figura 1). Nessa fase, a cultura da soja demanda maior quantidade de água devido a maior área foliar e a maior intensidade do metabolismo das plantas, como os processos fotossintéticos e de translocação de fotoassimilados para os grãos (SEDIYAMA et al., 2009; PROCÓPIO et al., 2014; CARMO et al., 2018). Isto pode ter contribuído para que os arranjos de plantas não proporcionassem incrementos na produtividade de grãos.

Já o aumento na população de plantas proporcionou acréscimo no acúmulo de massa seca e na altura de plantas no cultivar BRS Valiosa $\mathrm{RR}^{\circledR}$ (Figura 2), semelhante ao constatados em outros trabalhos de pesquisa com arranjo de plantas (BALBINOT JUNIOR et al., 2015; 2016). Era esperado que o maior porte e acúmulo de massa seca pudessem contribuir para a obtenção de maiores produtividades de grãos, fato não observado.

Além do mais, a cultivar BRS Valiosa $\mathrm{RR}^{\circ}$ possui como uma de suas principais características a alta capacidade de formação de folhas, com folíolos de maior tamanho quando comparada as cultivares de hábito de crescimento indeterminado (Perini et al., 2012). Estas características, aliadas ao aumento da população, contribuíram para a maior competição por luz, ocasionando o estiolamento das plantas (MODOLO et al., 2016; CARMO et al., 2018), o que ocasionou ausência de significância para o acúmulo de massa seca e altura de plantas. É oportuno destacar que o aumento na população pode favorecer a ocorrência de acamamento das plantas, principalmente para cultivares de maior porte (PROCÓPIO et al., 2014), o que não foi constatado com a BRS Valiosa $\mathrm{RR}^{\circledR}$.

Figura 2. Valores médios de massa seca da parte aérea* (MS) e altura de plantas (ALT) do cultivar BRS Valiosa $R^{\oplus}$ em função do espaçamento entrelinhas e da população de plantas, Rio Verde/GO, safra 2012/13.*Estádio $R_{6}$
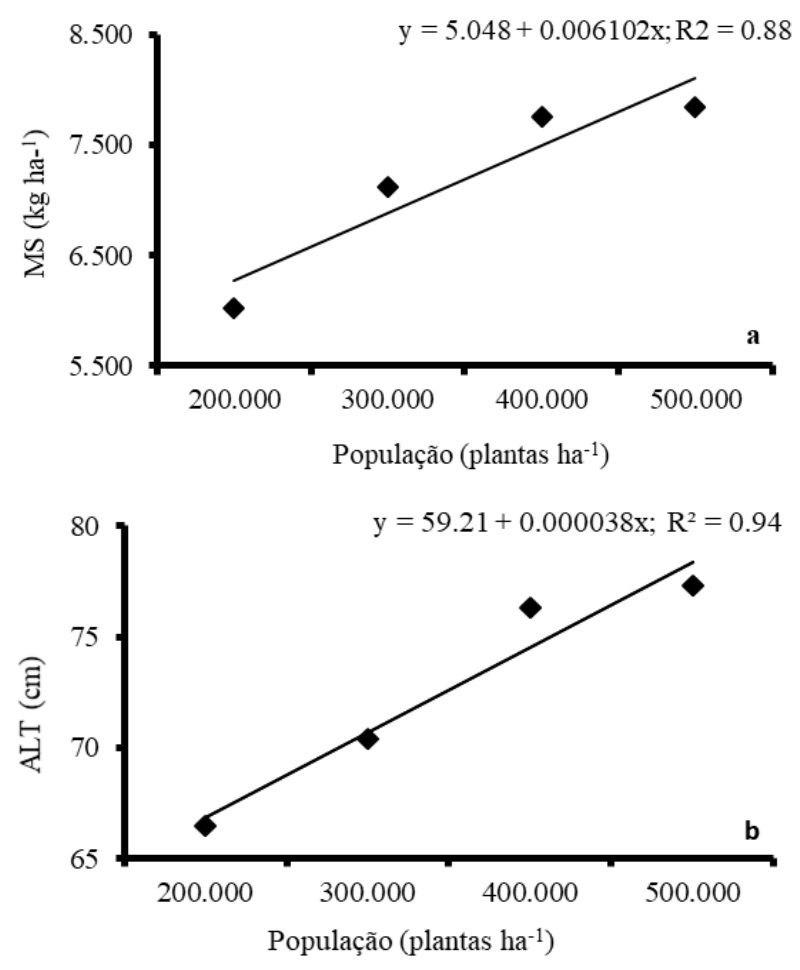

A altura de inserção da primeira vagem teve efeito da interação do espaçamento entrelinhas e da população de plantas (Tabela 1).
Neste caso, constatou-se maior valor no espaçamento de $40 \mathrm{~cm}$ em relação ao de $20 \mathrm{~cm}$ na população de 500.000 plantas ha $^{-1}$ (Tabela 2). 
A menor distância das plantas na linha no arranjo de 500.000 plantas $a^{-1}$, para o espaçamento de $40 \mathrm{~cm}$, ocasionou a maior competição por luz, estimulando 0 alongamento dos entrenós inferiores e consequentemente o aumento da altura da inserção da primeira vagem. Isto tem uma implicação prática pois maiores valores dessa variável fazem com que as vagens localizadas no terço inferior das plantas de soja sejam colhidas pela plataforma de corte das colheitadeiras. Consequentemente haverá menor proporção de vagens retidas nas hastes após a colheita, minimizando assim perdas com a colheita mecanizada da cultura (MAUAD et al., 2010; PROCÓPIO et al., 2014).

Tabela 2. Valores médios da altura de inserção da primeira vagem (AIV) e do número de vagens na haste principal (NVHP) da cultivar BRS Valiosa RR em função do espaçamento entrelinhas e da população de plantas, Rio Verde/GO, safra 2012/13.

\begin{tabular}{|c|c|c|c|c|c|}
\hline \multirow{2}{*}{$\begin{array}{c}\text { Espaçamento } \\
\text { entrelinhas }\end{array}$} & \multicolumn{4}{|c|}{--- População (plantas ha ${ }^{-1}$ ) --- } & \multirow{2}{*}{ Médias } \\
\hline & 200.000 & 300.000 & 400.000 & 500.000 & \\
\hline$(\mathrm{cm})$ & \multicolumn{4}{|c|}{$\operatorname{AIV}(\mathrm{cm})$} & \\
\hline 20 & 21,6 a & $21,3 \mathrm{a}$ & 21,7 a & $19,1 b$ & $20,9 \mathrm{a}$ \\
\hline 40 & $21,3 \mathrm{a}$ & $23,2 \mathrm{a}$ & $25,0 \mathrm{a}$ & 26,5 a & $24,0 \mathrm{a}$ \\
\hline $20 / 40$ & $22,5 \mathrm{a}$ & $21,7 \mathrm{a}$ & $26,8 \mathrm{a}$ & $23,6 a b$ & $23,6 \mathrm{a}$ \\
\hline $20 / 60$ & $21,3 \mathrm{a}$ & $21,8 \mathrm{a}$ & 24,3 a & $24,1 a b$ & $22,9 \mathrm{a}$ \\
\hline Médias & 21,7 & 22,0 & 24,4 & 23,3 & 22,9 \\
\hline \multicolumn{6}{|c|}{ NVHP } \\
\hline 20 & $29,1 a b$ & $27,2 \mathrm{a}$ & $25,3 a b$ & $23,7 \mathrm{a}$ & $26,3 a b$ \\
\hline 40 & $27,0 \quad b$ & $26,1 \mathrm{a}$ & $19,7 \quad b$ & 23,7 a & $24,1 \mathrm{~b}$ \\
\hline $20 / 40$ & 34,0 a & $26,1 \mathrm{a}$ & 26,3 a & $23,2 \mathrm{a}$ & $27,4 \quad a$ \\
\hline $20 / 60$ & $28,9 a b$ & 25,9 a & $22,8 a b$ & 20,9 a & $24,6 a b$ \\
\hline Médias & 29,7 & 26,3 & 23,5 & 22,9 & 25,6 \\
\hline
\end{tabular}

Semelhante à altura de inserção da primeira vagem, o número de vagens na haste principal apresentou interação significativa entre as fontes de variação testadas (Tabela 1). Os maiores valores foram observados no espaçamento de fileiras duplas $20 / 40 \mathrm{~cm}$ nas populações de 200.000 e 400.000 plantas ha $^{-1} \mathrm{em}$ relação ao espaçamento convencional $(40 \mathrm{~cm})$ (Tabela 2). Destaca-se que a formação de vagens na haste principal é fundamental para obtenção de maiores produtividades, principalmente quando se tem o cultivo de soja em áreas de primeiro ano de cultivo ou em solos de menor fertilidade (ROCHA et al., 2012). No entanto o maior número de vagens nos tratamentos supracitados não contribuiu para aumentos de produtividade, provavelmente em função da maior plasticidade fenotípica da BRS Valiosa $R^{\circledR}{ }^{\circledR}$ e do ambiente (semeadura em Rio Verde-GO em 23 de novembro) em que a soja foi cultivada.
Já o número total de vagens na haste principal, independentemente do número de grãos por vagem, não foi influenciado pelos espaçamentos entrelinhas (Tabela 1). Por outro lado, o aumento da população de plantas reduziu os valores dessas variáveis (Figura 3), sem, contudo, afetar a produtividade de grãos. Isto leva a crer na possibilidade de redução da população de plantas da BRS Valiosa RR', visto que o emprego de maiores populações implica em aumento nos custos de produção pelo aumento da quantidade de sementes. Fato semelhante é corroborado por Procópio et al. (2014) que evidenciaram que a redução da população de plantas proporcionou maior número de grãos por planta sem influenciar na produtividade de grãos em uma cultivar de soja de hábito de crescimento determinado (BRS 294 $\mathrm{RR}^{\circledR}$ ). 
Figura 3. Valore médios do número total de vagens na haste principal (NVHP), com três e dois grãos (Figura 3a), número de hastes secundárias (NHS) e de vagens nesta haste (NVHS) (Figuras 3b e 3c, respectivamente) da cultivar BRS Valiosa $\mathrm{RR}^{\circ}$ em função do espaçamento entrelinhas e da população de plantas, Rio Verde/GO, safra 2012/13.
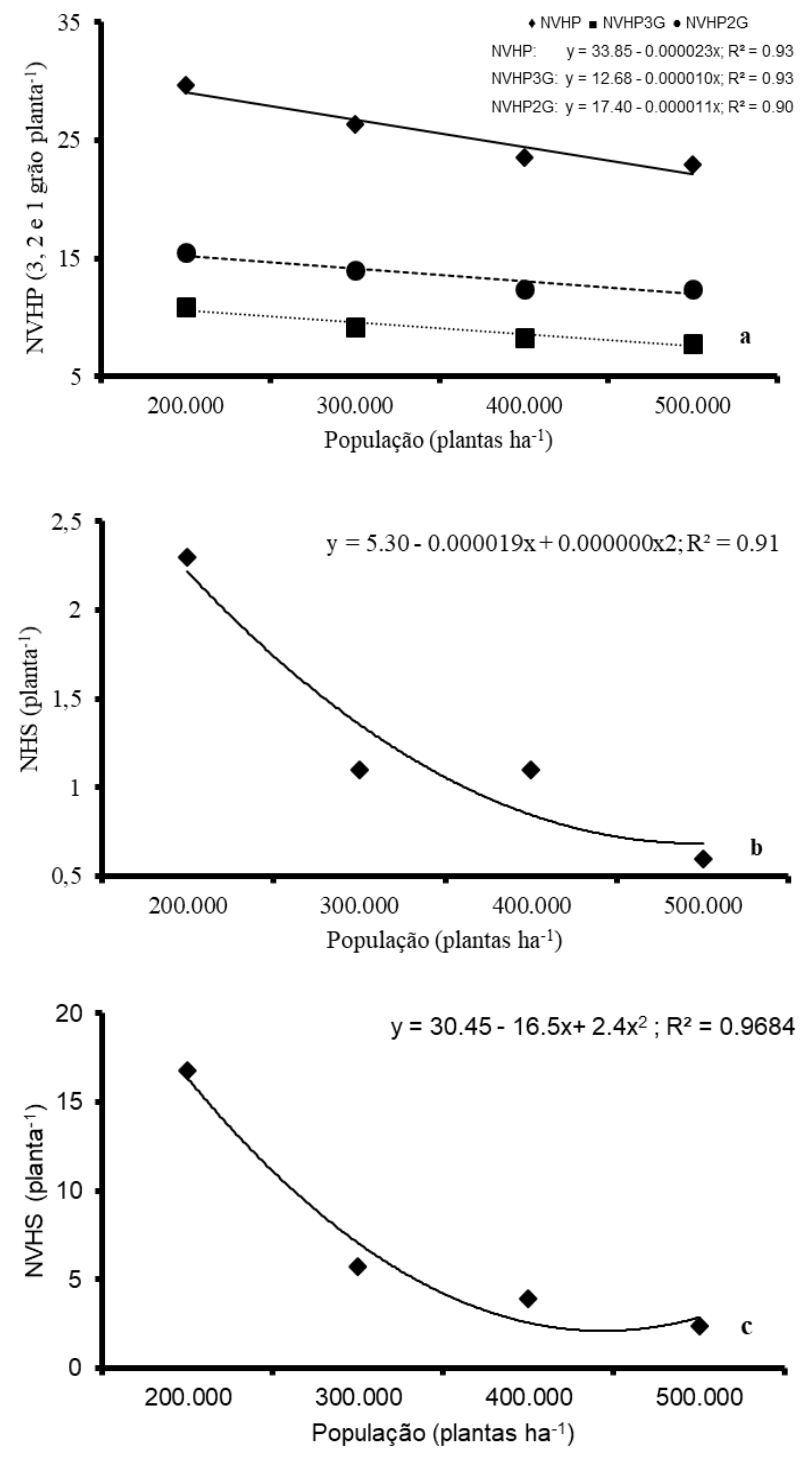

O aumento da população de plantas ocasionou redução do número de hastes secundárias (Figura 3b), bem como na formação de vagens nessas hastes (Figura 3c). Neste contexto, a interação entre os componentes de produtividade do cultivar BRS Valiosa $\mathrm{RR}^{\circledR}$ nas diferentes populações de plantas fez com que não fossem constatados efeitos para a produtividade de grãos, semelhantes aos registrados na literatura (KOMATSU et al., 2010; PROCÓPIO et al., 2014).

A redução do número de vagens nas hastes secundárias quando se aumentou a população de plantas é atribuída a maior competição intraespecífica das plantas na linha, como constatado por MAUAD et al. (2010) no cultivar Coodetec $219 \mathrm{RR}^{\circledR}$, também de hábito de crescimento determinado. Associado à alta plasticidade fenotípica da BRS Valiosa RR', condições menos favoráveis ao desenvolvimento das plantas, como menor disponibilidade de chuvas na fase de enchimento de grãos (Figura 1), limitam o aumento dos componentes de produtividade (LUDWIG et al., 2011), e consequentemente o aumento de produtividade de grãos da soja.

A partir dos resultados obtidos, pode-se notar que o cultivo da BRS Valiosa $\mathrm{RR}^{\circ}$ nos 
espaçamentos e populações de plantas empregadas neste trabalho não influenciam a produtividade de grãos. Isto torna mais relevante quando a implantação da soja ocorre em semeaduras tardias pelo atraso no estabelecimento do período chuvoso nos cerrados. Neste caso, há riscos de estiagem durante 0 estabelecimento das plântulas, podendo ocasionar a sua morte e implicar na ressemeadura da soja, o que onera bastante os custos de produção.
Sendo assim, cultivares de soja de hábito de crescimento determinado, de maior grupo de maturação e que apresentem maior plasticidade fenotípica, como o caso do cultivar BRS Valiosa $\mathrm{RR}^{\circledast}$, podem ser implantadas em menor população de plantas, independente do espaçamento entrelinhas, sem, contudo, haver diferenças na produtividade de grãos.

Tabela 3. Médias de produtividade (PROD), massa de mil grãos (M1000G), massa seca da parte aérea (MS), alturas de plantas (ALT) e de inserção da primeira vagem (AIV), número de vagens na haste principal (NVHP) com três (NVHP3G), dois (NVHP2G) e um grão (NVHP1G), número de hastes secundárias (NHS) e de vagens na haste secundária (NVHS) da variedade BRS Valiosa RR em função dos arranjos e populações de plantas, Rio Verde/GO, safra 2012/13.

\begin{tabular}{|c|c|c|c|c|c|c|}
\hline Variáveis & $\begin{array}{l}\text { PROD } \\
\left(\mathrm{kg} \mathrm{ha}^{-1}\right)\end{array}$ & & $\begin{array}{l}\text { M1000G } \\
\text { (g) }\end{array}$ & $\begin{array}{c}\text { MS } \\
\left(\mathrm{kg} \mathrm{ha}^{-1}\right)\end{array}$ & $\begin{array}{l}\text { ALT } \\
(\mathrm{cm})\end{array}$ & AIV \\
\hline Médias & 2.265 & & 144,60 & 7.184 & 72,60 & 22,90 \\
\hline Variáveis & NVHP & NVHP3G & NVHP2G & $\begin{array}{c}\text { NVHP1G } \\
\text {--- (unidades)--- }\end{array}$ & NHS & NVHS \\
\hline Médias & 25,60 & 9,10 & 13,60 & 2,80 & 1,30 & 7,20 \\
\hline
\end{tabular}

\section{Conclusões}

Os espaçamentos e as populações de plantas não influenciaram a produtividade e a massa de mil grãos do cultivar BRS Valiosa RR ${ }^{\circ}$.

Menor população de plantas $(66 \%$ do recomendado) proporcionou incrementos na formação de hastes secundárias e de vagens.

\section{Agradecimentos}

O presente trabalho foi realizado com apoio da Coordenação de Aperfeiçoamento de Pessoal de Nível Superior - Brasil (CAPES) Código de Financiamento 001, e pela FAPEG por meio de concessão de taxa de estudos para o primeiro autor.

\section{Referências}

BALBINOT JUNIOR, A. A.; PROCÓPIO, S. O.; NEUMAIER, N.; FERREIRA, A. S.; WERNER, F.; DEBIASI, H.; FRANCHINI J. C. Semeadura cruzada, espaçamento entre fileiras e densidade de semeadura influenciando o crescimento de duas cultivares de soja. Revista de Ciências Agroveterinárias, v. 15, n. 2, p. 083-093, 2016. https://doi.org/10.5965/223811711522016083

BALBINOT JUNIOR, A. A.; PROCÓPIO, S. O.; DEBIASI, H.; FRANCHINI, J. C.; PANISON, F.
Semeadura cruzada em cultivares de soja com tipo de crescimento determinado. Semina:Ciencias Agrarias, v. 36 , n. 3, p. $1215-$ 1225, $2015 . \quad$ https://doi.org/10.5433/16790359.2015v36n3p1215

BIANCHI, M. A.; FLECK, N. G.; LAMEGO, F. P.; AGOSTINETTO, D. Plant arrangement and soybean cultivar roles in weed interference results. Planta Daninha, v. 28, n. SPEC. ISSUE, p. 979-991, 2010. https://doi.org/10.1590/S0100$\underline{83582010000500006}$

BOARD, J. E.; KAHLON, C. S. Morphological responses to low plant population differ between soybean genotypes. Crop science, v. 53, n. 3, p. 1109-1119, 2013.

https://doi.org/10.2135/cropsci2012.04.0255

BRACHTVOGEL, E. L.; PEREIRA, F. R. S.; CRUZ, S. C. S.; BICUDO, S. J. Densidades populacionais de milho em arranjos espaciais convencional e equidistante entre plantas. Ciencia Rural, v. 39, n. 8, p. 2334-2339, 2009.

https://doi.org/10.1590/s0103$\underline{84782009005000193}$

CARMO, E. L.; BRAZ, G. B. P.; SIMON, G. A.; SILVA, 
A. G.; ROCHA, A. G. C. Soybean performance at different sowing times and plant distribution. Revista de Ciencias Agroveterinarias, v. 17, n. 1, p. 61-69, 2018.

https://doi.org/10.5965/223811711712018061

COX, W.; CHERNEY J. H. Growth and yield responses of soybean to row spacing and seeding rate. Agronomy Journal, v. 103, n. 1, p. 123-128, 2011. https://doi.org/10.2134/agronj2010.0316

CRUZ, S. C. S.; SENA JUNIOR, D. G.; SANTOS, D. M. A.; LUNEZZO, L. O.; MACHADO, C. G. Cultivo de soja sob diferentes densidades de semeadura e arranjos espaciais. Journal of Neotropical Agriculture, v. 3, n. 1, p. 1-6, 2016. https://doi.org/10.32404/rean.v3i1.431

KOMATSU, R. A.; GUADAGNIN, D. D.; BORGO, M. A. Efeito do espaçamento de plantas sobre o comportamento de cultivares de soja de crescimento determinado. Campo Digital, v. 5, n. 1, p. 50-55, 2010.

LUDWIG, M. P.; DUTRA, L. M. C.; LUCCA FILHO, O. A.; ZABOT, L.; JAUER, A.; UHRY, D. Populações de plantas na cultura da soja em cultivares convencionais e Roundup ReadyTM. Revista Ceres, v. 58, n. 3, p. 305-313, 2011. https://doi.org/10.1590/S0034-

737X2011000300010

MADALOSSO, M. G.; DOMINGUES, L. S.; DEBORTOLI, M. P.; LENZ, G.; BALARDIN, R. S. Cultivares, espaçamento entrelinhas e programas de aplicação de fungicidas no controle de Phakopsora pachyrhizi sidow em soja. Ciencia Rural, v. 40, n. 11, p. 2256-2261, 2010. https://doi.org/10.1590/S0103-

$\underline{84782010001100002}$

MAUAD, M.; SILVA, T. L. B.; NETO, A. I. A.; ABREU, V. G. Influência da densidade de semeadura sobre características agronômicas na cultura da soja. Agrarian, v. 3, n. 9, p. 175-181, 2010

MODOLO, A.J.; SCHIDLOWSKI, L. L.; STORCK, L.; BENIN, G.; VARGAS, T. O.; TROGELLO, E. Rendimento de soja em função do arranjo de plantas. BRAZILIAN JOURNAL OF AGRICULTURE Revista de Agricultura, v. 91, n. 3, p. 216, 2016. https://doi.org/10.37856/bja.v91i3.143
PERINI, L.; FONSECA, N. S.; DESTRO, D.; PRETE, C. E. C. Componentes da produção em cultivares de soja com crescimento determinado e indeterminado. Semina:Ciencias Agrarias, v. 33, n. SUPPL.1, p. 2531-2544, 2012. https://doi.org/10.5433/1679-

0359.2012v33Supl1p2531

PROCÓPIO, S. O.; BALBINOT JUNIOR, A. A.; DEBIASI, H.; FRANCHINI, J. C.; PANISON, F. Semeadura em fileira dupla e espaçamento reduzido na cultura da soja. Revista Agro@Mbiente on-Line, v. 8, n. 2, p. 212, 2014. https://doi.org/10.18227/1982-

8470ragro.v8i2.1469

PROCÓPIO, S. O.; BALBINOT, A. A.; DEBIASI, H.; FRANCHINI, J. C.; PANISON, F. Plantio cruzado na cultura da soja utilizando uma cultivar de hábito de crescimento indeterminado. Revista de Ciências Agrarias - Amazon Journal of Agricultural and Environmental Sciences, v. 56, n. 4, p. 319-325, 2013.

https://doi.org/10.4322/rca.2013.048

ROCHA, R. S.; DA SILVA, J. A. L.; NEVES, J. A.; SEDIYAMA, T.; TEIXEIRA, R. de C. Desempenho agronômico de variedades e linhagens de soja em condições de baixa latitude em Teresina-PI. Revista Ciencia Agronomica, v. 43, n. 1, p. 154162, $2012 . \quad$ https://doi.org/10.1590/S180666902012000100019

RITCHIE, W. S.; BENSON, G. O.; LUPKES, S.; SALVADOR, R. J.; RITCHIE, S. W.; RITCHIE, B. W.; SALVADOR, R. How a corn plant develops: special report no 48. lowa: lowa State University of Science and Technology Cooperative Extension Service, 1993.

SEDIYAMA, T.; TEIXEIRA, R. C.; BARROS, H. B. Tecnologias de produção $e$ usos da soja. Londrina: Mecenas, 2009. v. 1.

SANTOS, H. G.; JACOMINE, P. K. T.; DOS ANJOS, L. H. C.; OLIVEIRA, V. A.; LUMBRERAS, J. F.; COELHO, M. R.; CUNHA, T. J. F. Sistema brasileiro de classificação de solos. Brasília, DF: Embrapa, 2013.

SILVA, L. S. .; MOURA, M. C. C. L. .; VALADARES, R. N. .; SILVA, R. G. .; DA SILVA, A. F. A. Plantio, na microrregião de Chapadinha, Nordeste selection soybean varieties function of density planting in microregion of Chapadinha, ne Maranhenses. 
Agropecuária Científica No Semi-Árido, v. 06, p. 7-14, 2010.

VILELA, L.; MARTHA, G. B.; MACEDO, M. C. M.; et al. Sistemas de integração lavoura-pecuaria na região do Cerrado. Pesquisa Agropecuaria Brasileira, v. 46, n. 10, p. 1127-1138, 2011.

https://doi.org/10.1590/S0100-

$\underline{204 \times 2011001000003}$

ZITO, R. K.; MELLO FILHO, O. L.; NUNES JUNIOR, J.; PIMENTA, C.; MEYER, M.; HIROSE, E.; GASPRE, $M$. Cultivares de soja: macrorregiões 3,4 e 5 Goiás e Região Central do Brasil. Embrapa SojaFôlder/Folheto/Cartilha (INFOTECA-E), 2012. 